\title{
Estimation of fog deposition on epiphytic bryophytes in a subtropical montane forest ecosystem in northeastern Taiwan
}

\author{
Shih-Chieh Chang ${ }^{\text {a,* }}$, I-Ling Lai ${ }^{\text {b }}$, Jiunn-Tzong $\mathrm{Wu}^{\text {a,b }}$ \\ anstitute of Botany, Academia Sinica, 11564 Taipei, Taiwan \\ bepartment of Botany, National Taiwan University, 10673 Taipei, Taiwan
}

Received 4 October 2001; received in revised form 8 March 2002; accepted 14 March 2002

\begin{abstract}
The fog meteorology, fog chemistry and fog deposition on epiphytic bryophytes were investigated from July 2000 to June 2001 in the Yuanyang Lake forest ecosystem. The elevation of the site ranges from 1650 to $2420 \mathrm{~m}$, at which the high frequency of fog occurrence throughout the year has been thought to be of benefit to the establishment of the primary Taiwan yellow cypress forest [Chamaecyparis obtusa var. formosana (Hayata) Rehder] and to the extensive growth of the epiphytic bryophytes. A weather station including a visibility sensor and an active fog collector was installed for fog meteorological and chemical study. The fog deposition rate on epiphytic bryophytes was estimated by measuring the increase rate in plant weight when exposed to fog. Average fog duration of 4.7 and $11.0 \mathrm{~h}$ per day was measured in summer months (June to August) and the rest of the year, respectively. November 2000 was the foggiest month in which the average fog duration reached $14.9 \mathrm{~h}$ per day. The ionic composition of fog water revealed that the area was less polluted than expected from literature data. The in situ exposure experiments done with the dominant epiphytic bryophytes showed an average fog deposition rate of $0.63 \mathrm{~g} \mathrm{H}_{2} \mathrm{O} \mathrm{g}{ }^{-1} \mathrm{~d}$. w. $\mathrm{h}^{-1}$, which approximated $0.17 \mathrm{~mm} \mathrm{~h}^{-1}$ at the stand scale. The nutrient fluxes estimated for February 2001 showed that for all ions, more than $50 \%$ of the ecosystem input was through fog deposition. These results demonstrate the importance of epiphytic bryophytes and fog deposition in nutrient cycling of this subtropical montane forest ecosystem. The incorporation of fog study in the long-term ecosystem research projects is necessary in this area.
\end{abstract}

(C) 2002 Elsevier Science B.V. All rights reserved.

Keywords: Cloud forest; Epiphytic bryophytes; Fog chemistry; Fog deposition; Subtropics

* Corresponding author. Present address: Institute of Natural Resources, National Dong Hwa University, 97441 Hualien, Taiwan. Fax: +886-3-8662533.

E-mail address: scchang@mail.ndhu.edu.tw (S.-C. Chang). 


\section{Introduction}

In the forest ecosystems of coastal areas and the higher mountains, fog deposition has been recognized as an important component of the hydrological and nutrient cycling (Elias et al., 1995; Dawson, 1998; Weathers et al., 2000). The frequent occurrence of fog may result in the special structure and functioning of the tropical montane cloud forest (TMCF) (Bruijnzeel and Veneklaas, 1998). Among others, the abundance of epiphytic bryophytes is a typical feature found in the TMCF (Rhoades, 1995). The epiphytic bryophytes may help retaining water in the canopy and thus provide a suitable germination bed and anchorage for the vascular epiphytes and seedlings of the vegetation. While the biomass and biodiversity of epiphytic bryophytes were much investigated in montane forests (Freiberg and Freiberg, 2000), little is known about their role in the nutrient cycling of the ecosystems (Coxson and Nadkarni, 1995; Clark et al., 1998), particularly, the influence of epiphytic bryophytes on fog deposition and vice versa. Due to the difficulty of direct measurement, our knowledge about fog deposition in forest ecosystems is accompanied with more uncertainty compared to precipitation deposition. Some methodologies such as micrometeorological modeling (Lovett, 1984; Saxena et al., 1989; Walmsley et al., 1996) and eddy covariance measuring systems (Vermeulen et al., 1997; Wrzesinsky et al., 2001) were widely used to estimate the fog deposition rate. However, these methods seem not applicable, when we are only interested in the fog deposition on some portion of the canopy, in our case, the epiphytic bryophytes. Even if models could be developed to differentiate the fog deposition into various canopy components, validation measurements would still be necessary.

Our study site, the Yuanyang Lake ecosystem, is located in the mountainous regions of northeastern Taiwan and experiences frequent fog immersion. Our previous study (Wu et al., 2001) showed that epiphytic bryophytes played an important role in the acidification of this ecosystem. The frequent occurrence of fog and the large amount of epiphytic bryophytes were believed to be important factors for the establishment and regeneration of the forest. The aim of this paper was to gather the fog meteorological and chemical data at this site and to estimate the fog deposition on epiphytic bryophytes using an in situ exposure method.

\section{Materials and methods}

\subsection{Site description}

The fog-monitoring program and fog deposition experiments were conducted at the Yuanyang Lake site $\left(24^{\circ} 35^{\prime} \mathrm{N}, 121^{\circ} 24^{\prime} \mathrm{E}\right)$ in northeastern Taiwan. This site is a watershed with an area of 374 ha ranging from 1650 to $2420 \mathrm{~m}$ in altitude. The watershed was declared as a nature preserve due to the presence of the subalpine lake, the Yuanyang Lake and the surrounding old-growth Taiwan yellow cypress forest [Chamaecyparis obtusa var. formosana (Hayata) Rehder]. It has been virtually disturbed little by human activities for a long time. For these reasons, as the government started the Taiwan Ecological Research Network (TERN) in 1993, this watershed was chosen as 
one of the five long-term ecosystem research sites to represent the middle-altitude forest ecosystems in Taiwan.

According to the weather data recorded at this site, the mean annual temperature from 1993 to 2000 is $13{ }^{\circ} \mathrm{C}$. The annual rainfall varies drastically during this period from less than 2000 to over $5000 \mathrm{~mm}$, depending on the number and strength of typhoons that fall on Taiwan. There is no apparent wet and dry seasons. However, the precipitation types differentiate between summer and winter: the source of rainfall in summer is mostly the orographic precipitation and the typhoons, while in winter, the precipitation is mainly brought by the northeastern monsoon.

\subsection{Fog meteorology and chemistry}

A weather station was installed in summer 2000, including a MIRA visibility sensor 3544 (Aanderaa instruments, Norway), an active fog collector and ancillary weather monitoring sensors. The instruments were mounted on a 3-m-high tower near the lakeshore, with a distance of $>50 \mathrm{~m}$ from the forest. Three rain gauges were installed beside the tower for collecting bulk precipitation.

Since there is no electricity supply at the Yuanyang Lake site, a battery-powered 12 VDC electric fan was used in the active fog collector. The collecting unit contains 93 vertical nylon strands, which are $17 \mathrm{~cm}$ long and $0.5 \mathrm{~mm}$ in diameter, spaced $0.7 \mathrm{~mm}$ apart. Since nylon may absorb nitrate from solution, the strand material was changed to Teflon in July 2001. However, no apparent increase in nitrate concentration was found in fog water. The electric fan of the fog collector was automatically switched on when the visibility was lower than $500 \mathrm{~m}$. For reducing the power consumption from the batteries, however, the electric fan was switched on/off at a 5-min/5-min rhythm, as long as the visibility remained low.

Fog water and bulk precipitation were collected every 2 weeks. The conductivity and $\mathrm{pH}$ were analyzed in the field. Then, the samples were filtered $(0.45 \mu \mathrm{m})$ and brought to the laboratory for chemical analysis. The $\mathrm{Na}^{+}, \mathrm{K}^{+}, \mathrm{Ca}^{2+}$ and $\mathrm{Mg}^{2+}$ concentrations were analyzed using atomic absorption spectrometry. The $\mathrm{Cl}^{-}, \mathrm{NO}_{3}{ }^{-}$and $\mathrm{SO}_{4}^{2-}$ concentrations were determined using ion chromatography. $\mathrm{NH}_{4}^{+}$concentration was determined using a spectrophotometer $(655 \mathrm{~nm})$ after chemical reactions (for details see Rump, 1998).

\subsection{Fog deposition experiments}

The rates of fog deposition were studied in the field. The increase in plant weight under foggy conditions was used as a measure of fog deposition. Dominant species of epiphytic bryophytes were collected and air dried. Under foggy conditions, 15-20 g of bryophytes were placed in a stainless rack mounted upon an electric balance, which was fixed on the weather station at the same height as the visibility sensor. The weight data were recorded continuously in a portable computer and lasted for about $1.5 \mathrm{~h}$. The whole measuring system was well protected against the influence of rainwater. After the deposition experiments, the dry weight $\left(65^{\circ} \mathrm{C}\right.$ oven dried) of the plants was measured and used for the calculation of fog deposition rate for individual bryophyte species. To estimate the 
fog deposition rate on the epiphytic bryophytes in the forest canopy, we multiplied the average fog deposition rate of the dominant bryophyte species with the estimated $2.7 \mathrm{t}$ ha $^{-1}$ bryophytes biomass on the Taiwan yellow cypress trees.

\section{Results}

\subsection{Fog meteorology}

At the Yuanyang Lake site, the frequency of fog occurrence was particularly high. During the period of observation from July 2000 to June 2001, the total duration of fog was $3437 \mathrm{~h}$, about $39.2 \%$ of the total time. The occurrence of fog exhibited a strong seasonal variation (Fig. 1a): the summer months (June to August) had average daily fog duration of $4.7 \mathrm{~h}$, while the rest of the year had $11.0 \mathrm{~h}$ (Fig. 1a). The foggy weather lasted
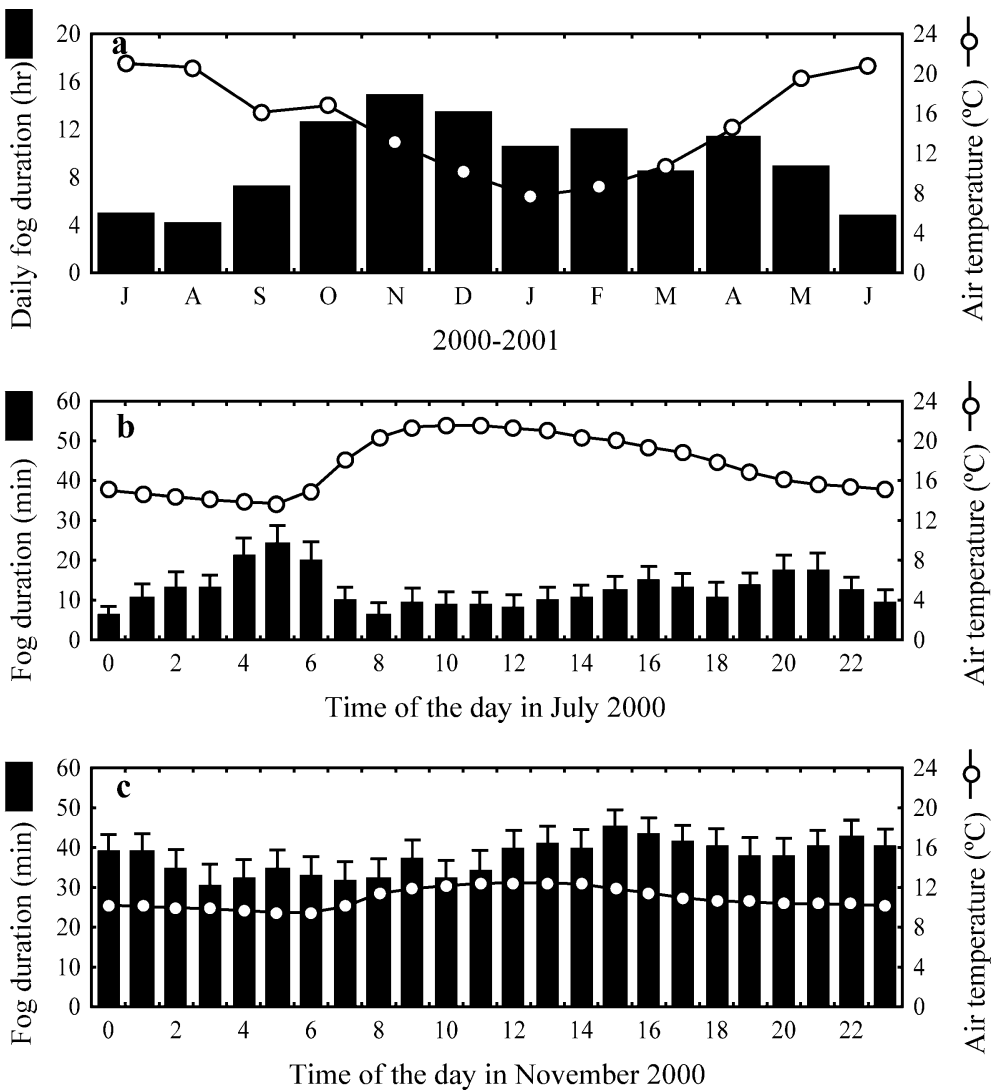

Fig. 1. Fog occurrence at the Yuanyang Lake site showing (a) the seasonal variation of average daily fog duration and air temperature from July 2000 to June 2001 and the averaged distribution of fog and air temperature within a day in (b) July 2000 and (c) November 2000. The error bars represent standard error of mean. 
for the whole winter and spring, reached its peak in November and abruptly turned to a more sunny weather in the beginning of summer.

Another noticeable character of fog at the Yuanyang Lake site was the seasonal variation of the distribution within a day. A peak of fog was frequently observed at 5 a.m. during the summer time, possibly a result of the radiation fog (Fig. 1b). In autumn, on the other hand, fog occurred more or less uniformly within a day (Fig. 1c).

\subsection{Fog chemistry}

At the remote Yuanyang Lake site, the ion concentrations in fog water were generally very low. The medians and ranges of the ion concentrations of the 25 samples from July 2000 to June 2001 are given in Table 1. The ion with the highest concentration for fog water and bulk precipitation was $\mathrm{SO}_{4}^{2-}$, which amounted to 108.1 and $12.3 \mu \mathrm{eq} 1^{-1}$, respectively. The $\mathrm{SO}_{4}^{2-}$ concentration for fog water was 8.8 times that for the bulk precipitation. The other two anions, $\mathrm{Cl}^{-}$and $\mathrm{NO}_{3}^{-}$, were much less concentrated in fog water and bulk precipitation than $\mathrm{SO}_{4}^{2-}$. The $\mathrm{Cl}^{-}$concentration in fog water was 10.7 times that in bulk precipitation, and the $\mathrm{NO}_{3}{ }^{-}$concentration 5.7 times.

The dominant cation in fog water was $\mathrm{H}^{+}$, followed by $\mathrm{Ca}^{2+}, \mathrm{Na}^{+}, \mathrm{NH}_{4}^{+}, \mathrm{Mg}^{2+}$ and $\mathrm{K}^{+}$. The cations in the bulk precipitation generally had the same order except that $\mathrm{NH}_{4}^{+}$ had the second highest concentration. Like the anions, the cation concentrations in the fog water were much higher than those in the bulk precipitation. The charge of the fog water was relatively well balanced, with total anion of $170.4 \mu \mathrm{eq} 1^{-1}$ and total cation $156.1 \mu \mathrm{eq}$ $1^{-1}$.

\subsection{Fog deposition}

The epiphytic bryophytes exhibited an excellent ability to capture fog droplets. During an in situ exposure experiment, for example, $15.7 \mathrm{~g}$ of Bazzania fauriana (Steph) Hatt.

Table 1

Median, minimum and maximum values of $\mathrm{pH}$, conductivity $\left(\mu \mathrm{S} \mathrm{cm}{ }^{-1}\right)$ and main ion concentrations $\left(\mu \mathrm{eq} 1^{-1}\right)$ in bulk precipitation and fog water from July 2000 to June 2001 at the Yuanyang Lake site $(N=25$; n.d.: not detectable)

\begin{tabular}{|c|c|c|c|c|c|c|}
\hline & \multicolumn{3}{|c|}{ Bulk precipitation } & \multicolumn{3}{|l|}{ Fog } \\
\hline & Median & Minimum & Maximum & Median & Minimum & Maximum \\
\hline $\mathrm{pH}$ & 5.00 & 4.14 & 7.09 & 4.28 & 3.33 & 7.76 \\
\hline Conductivity & 9 & 3 & 45 & 62 & 10 & 326 \\
\hline $\mathrm{H}^{+}$ & 10 & 0.08 & 72 & 52 & 0.02 & 468 \\
\hline $\mathrm{Na}^{+}$ & 1.8 & n.d. & 21.3 & 29.5 & 3.6 & 169.5 \\
\hline $\mathrm{K}^{+}$ & 1.1 & n.d. & 6.1 & 9.0 & n.d. & 29.3 \\
\hline $\mathrm{Ca}^{2+}$ & 3.7 & 1.1 & 22.9 & 30.0 & 3.1 & 228.6 \\
\hline $\mathrm{Mg}^{2+}$ & 1.5 & 0.6 & 8.7 & 12.9 & 1.5 & 66.7 \\
\hline $\mathrm{NH}_{4}^{+}$ & 4.4 & n.d. & 37.8 & 22.2 & n.d. & 292.4 \\
\hline $\mathrm{Cl}^{-}$ & 3.2 & n.d. & 25.2 & 34.3 & 2.2 & 206.8 \\
\hline $\mathrm{NO}_{3}^{-}$ & 4.9 & 0.1 & 42.5 & 27.9 & n.d. & 251.4 \\
\hline $\mathrm{SO}_{4}^{2-}$ & 12.3 & 2.3 & 87.1 & 108.1 & 9.1 & 744.8 \\
\hline
\end{tabular}




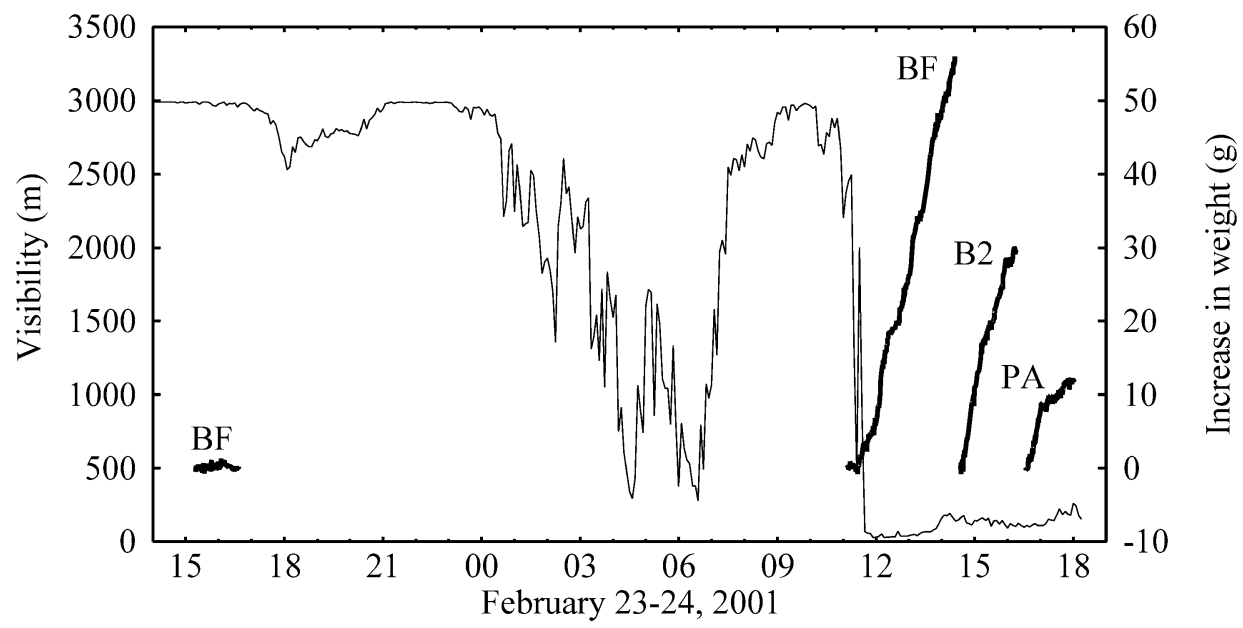

Fig. 2. In situ exposure experiment showing the change in bryophyte weights (thick lines) under different weather conditions. (BF: B. fauriana; B2: Bazzania sp. 2; PA: Pleurozia acinosa). Visibility (thin line) lower than $1000 \mathrm{~m}$ represents a foggy condition.

increased its weight by $55.3 \mathrm{~g}$, an amount of 3.5 times its air-dried weight (Fig. 2). The water-saturated plant bodies began to drip the fog water onto the surface of the balance, while they still continued capturing the fog water from the air. The fog capturing rates seemed not much influenced by the extent of surface wetness of the plants, as shown by the linear increase in plant weight throughout the experiment. In contrast to the foggy weather, the same amount of $B$. fauriana did not change its weight during a sunny day.

The ability of bryophytes to capture fog varied from species to species. Table 2 displays that the fog capturing rates varied from 0.23 to $1.28 \mathrm{~g} \mathrm{H}_{2} \mathrm{O} \mathrm{g}^{-1} \mathrm{~d} . \mathrm{w} \mathrm{h}^{-1}$, giving an average of $0.63 \mathrm{~g} \mathrm{H}_{2} \mathrm{O} \mathrm{g}^{-1} \mathrm{~d}$. w. $\mathrm{h}^{-1}$, which was significantly higher than that measured

Table 2

Fog-absorbing rates of the dominant epiphytic bryophytes and the leaves of Taiwan yellow cypress during a dense fog event in February 24, 2001 at the Yuanyang Lake site

\begin{tabular}{ll}
\hline Species & $\left.\begin{array}{l}\text { Fog-absorbing rate } \\
\left(\mathrm{g} \mathrm{H}_{2} \mathrm{O} \mathrm{g}\right.\end{array} \mathrm{d} . \mathrm{w} . \mathrm{h}^{-1}\right)$ \\
\hline Bryophytes & 1.28 \\
Bazzania fauriana & 0.90 \\
Bazzania sp. 2 & 0.67 \\
Pleurozia acinosa & 0.59 \\
Mastigophora diclados & 0.58 \\
Schistochila acuminata & 0.42 \\
Dicranoloma blumii & 0.38 \\
Scapania sp. 1 & 0.23 \\
Bazzania sp. 1 & 0.63 \\
Average of bryophytes & 0.30 \\
Chamaecyparis obtusa & \\
var. formosana (Hayata) Rehder & \\
\hline
\end{tabular}




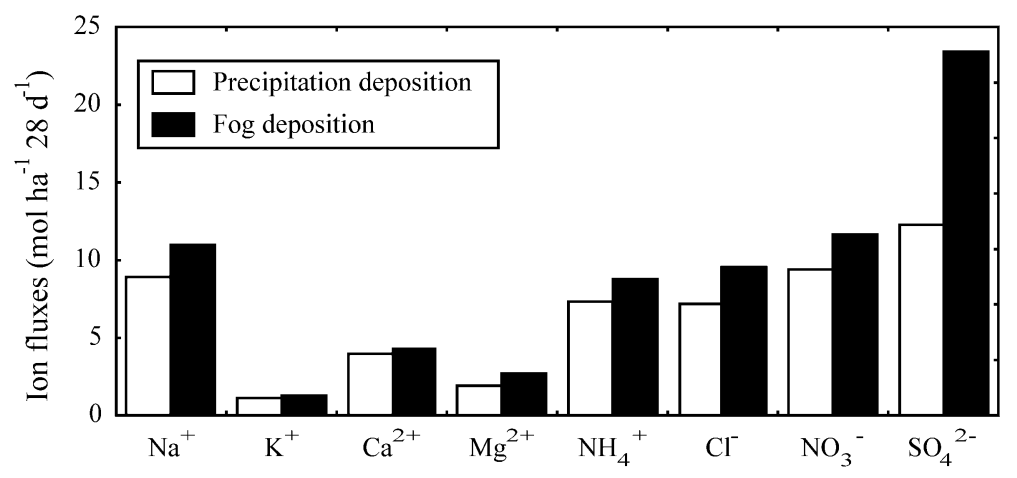

Fig. 3. Comparison of fog deposition on epiphytic bryophytes and bulk precipitation deposition for major ions in February 2001 at the Yuanyang Lake site.

for the leaves of the Taiwan yellow cypress $\left(0.30 \mathrm{~g} \mathrm{H}_{2} \mathrm{O} \mathrm{g}{ }^{-1} \mathrm{~d}\right.$. w. $\left.\mathrm{h}^{-1}\right)$. Multiplying the $2.7 \mathrm{t} \mathrm{ha}^{-1}$ bryophyte biomass with the $0.63 \mathrm{~g} \mathrm{H}_{2} \mathrm{O} \mathrm{g}{ }^{-1} \mathrm{~d}$. w. $\mathrm{h}^{-1}$, we obtained an estimation of stand-scale fog deposition rate of $0.17 \mathrm{~mm} \mathrm{~h}^{-1}$.

The nutrient input through fog deposition at the stand scale was further estimated for February 2001, the same time period we performed the in situ exposure experiments. In this month, the total fog duration was $333 \mathrm{~h}$, which possibly brought in $57 \mathrm{~mm}$ fog deposition on the epiphytic bryophytes. At the same period of time, the bulk precipitation recorded by the rain gauge summed up to $101 \mathrm{~mm}$. Without considering the fog deposition on the leaves of the trees, the fog deposition on epiphytic bryophytes alone was $36 \%$ of the total atmospheric deposition. The chemical composition of fog and bulk precipitation for this month was represented by the average ion concentrations of the sampling days 9th and 24th of February. Fig. 3 demonstrates the ion fluxes for fog deposition and compares them with those for the bulk precipitation. The ion that is most remarkable is $\mathrm{SO}_{4}^{2-}$, which entered the forest ecosystem through fog at the rate of $23.3 \mathrm{~mol} \mathrm{ha}^{-1} 28 \mathrm{day}^{-1}$, almost twice the value of precipitation deposition. For all other ions that we measured, the atmospheric fluxes through fog deposition were slightly higher than those through precipitation deposition.

\section{Discussion and conclusions}

Compared with literature data (Eckardt and Schemenauer, 1998; Anderson et al., 1999; Wrzesinsky and Klemm, 2000), the Yuanyang Lake site was found to be one of the most "clean" sites with very low ion concentrations in fog water and bulk precipitation. Although the Yuanyang Lake site is only some tens of kilometers away from the heavily industrialized west part of the island, the air pollutants seem not to be transported across the mountain range that lies on the west side of the site. On the other hand, the local I-Lan County of the northeastern Taiwan, which only has some small factories and moderate agriculture, contributes to the low level of ion concentrations in fog water. Since this paper presented the first fog study in the long-term ecosystem 
research projects of Taiwan, we have no information about fog chemistry in other ecosystems around the island. The Fu-Shan research site located $30 \mathrm{~km}$ to the northeast of Yuanyang Lake site, however, also exhibited relatively low $\mathrm{SO}_{4}^{2-}$ and $\mathrm{NO}_{3}^{-}$ concentrations in the bulk precipitation (Lin et al., 1997).

The dominant bryophyte species that we used for the exposure experiments exhibit noticeable morphological variation. In general the leafy liverworts possessed higher fogcapturing rates than the moss species (Dicranoloma blumii). The extent to which the leaves overlap might further be crucial for the diverse fog absorption rates among the liverworts (Table 2).

The rate of fog deposition on the epiphytic bryophytes was estimated to be $0.17 \mathrm{~mm}$ $\mathrm{h}^{-1}$ in the canopy of the Taiwan yellow cypress forest. This rate was lower but generally on the same order of magnitude as the results from other studies, in which the deposition rates were calculated for the whole ecosystems either by micrometeorological models (Lovett, 1984; Saxena et al., 1989; Walmsley et al., 1996) or measured by an eddy covariance system (Vermeulen et al., 1997). If we take into account the fog deposition on the large amount of leaves of the Taiwan yellow cypress (leaf biomass more than 20 times higher than the epiphyte biomass), the deposition rate on the canopy might be up to $2 \mathrm{~mm}$ $\mathrm{h}^{-1}$.

The method that we used to estimate the fog deposition rate might be influenced by a number of parameters such as the liquid water content (LWC) of the fog and the wind velocity, which was recognized by the substantial variation of absorption rates in different exposure experiments. The fog absorption rates on epiphytic bryophytes (Table 2) and thus the fog deposition rate extrapolated for February 2001 might be considered as maximum values, since they were derived from an extremely foggy condition. The $333 \mathrm{~h}$ of fog occurrence used for upscaling included certainly foggy conditions with lower liquid water content and milder wind. Nevertheless, the results of this paper were obtained based on sound reasoning and give a first insight into the role of the epiphytic bryophytes in the context of fog deposition in a subtropical forest ecosystem. In order to get a more accurate estimation of the deposition rate and to extend the estimation for a longer period of time, the relation between the micrometeorological parameters and the fog-capturing rates for the plant bodies will be further studied. An application of a micrometeorological model to the Yuanyang Lake site is also under planning.

\section{Acknowledgements}

This work was supported by the Institute of Botany, Academia Sinica. We would like to thank Mr. J.C. Chen for the help in field works and Mr. Y.F. Wang for the chemical analysis.

\section{References}

Anderson, J.B., Baumgardner, R.E., Mohnen, V.A., Bowser, J.J., 1999. Cloud chemistry in the eastern United States, as sampled from three high-elevation sites along the Appalachian Mountains. Atmos. Environ. 33, $5105-5114$. 
Bruijnzeel, L.A., Veneklaas, E.J., 1998. Climatic conditions and tropical montane forest productivity: the fog has not lifted yet. Ecology 79, 3-9.

Clark, K.L., Nadkarni, N.M., Gholz, H.L., 1998. Growth, net production, litter decomposition, and net nitrogen accumulation by epiphytic bryophytes in a tropical montane forest. Biotropica 30, 12-23.

Coxson, D.S., Nadkarni, N.M., 1995. Ecological roles of epiphytes in nutrient cycles of forest ecosystems. In: Lowman, M.D., Nadkarni, N.M. (Eds.), Forest Canopies. Academic Press, San Diego, CA, pp. 495-543.

Dawson, T.E., 1998. Fog in the California redwood forest: ecosystem inputs and use by plants. Oecologia 117, $476-485$.

Eckardt, F.D., Schemenauer, R.S., 1998. Fog water chemistry in the Namib Desert, Namibia. Atmos. Environ. 32, $2595-2599$.

Elias, V., Tesar, M., Buchtele, J., 1995. Occult precipitation: sampling, chemical analysis and process modeling in the Sumava Mts. (Czech Republic) and in the Taunus Mts. (Germany). J. Hydrol. 166, 409-420.

Freiberg, M., Freiberg, E., 2000. Epiphyte diversity and biomass in the canopy of lowland and montane forests in Ecuador. J. Trop. Ecol. 16, 673-688.

Lin, T.C., Hamburg, S.P., King, H.B., Hsia, Y.J., 1997. Spatial variability of throughfall in a subtropical rain forest in Taiwan. J. Environ. Qual. 26, 172-180.

Lovett, G.M., 1984. Rates and mechanisms of cloud water deposition to a subalpine balsam fir forest. Atmos. Environ. 18, 361-371.

Rhoades, F.M., 1995. Nonvascular epiphytes in forest canopies: worldwide distribution, abundance, and ecological roles. In: Lowman, M.D., Nadkarni, N.M. (Eds.), Forest Canopies. Academic Press, San Diego, CA, pp. $353-408$.

Rump, H.H., 1998. Laborhandbuch für die Untersuchung von Wasser, Abwasser und Boden. Wiley-VCH, Weinheim, pp. 89-90.

Saxena, V.K., Stogner, R.E., Hendler, A.H., DeFelice, T.P., Yeh, R.J.Y., Lin, N.H., 1989. Monitoring the chemical climate of the Mt. Mitchell State Park for evaluation of its impact on forest decline. Tellus 41B, 92-109.

Vermeulen, A.T., Wyers, G.P., Römer, F.G., Van Leeuwen, N.F.M., Draaijers, G.P.J., Erisman, J.W., 1997. Fog deposition on a coniferous forest in The Netherlands. Atmos. Environ. 31, 375-386.

Walmsley, J.L., Schemenauer, R.S., Bridgman, H.A., 1996. A method for estimating the hydrologic input from fog in mountainous terrain. J. Appl. Meteorol. 35, 2237-2249.

Weathers, K.C., Lovett, G.M., Likens, G.E., Caraco, N.F.M., 2000. Cloudwater inputs of nitrogen to forest ecosystems in southern Chile: forms, fluxes, and sources. Ecosystems 3, 590-595.

Wrzesinsky, T., Klemm, O., 2000. Summertime fog chemistry at a mountainous site in central Europe. Atmos. Environ. 34, 1487-1496.

Wrzesinsky, T., Thalmann, E., Burkard, R., Eugster, W., Klemm, O., 2001. Fog deposition of nutrients and pollutants to a montane forest site. Proceedings of the Second International Conference on Fog and Fog Collection, St. John's, Canada, 15-20 July 2001, pp. 169-172.

Wu, J.T., Chang, S.C., Wang, Y.S., Wang, Y.F., Hsu, M.K., 2001. Characteristics of the acidic environment of the Yuanyang Lake (Taiwan). Bot. Bull. Acad. Sin. 42, 17-22. 